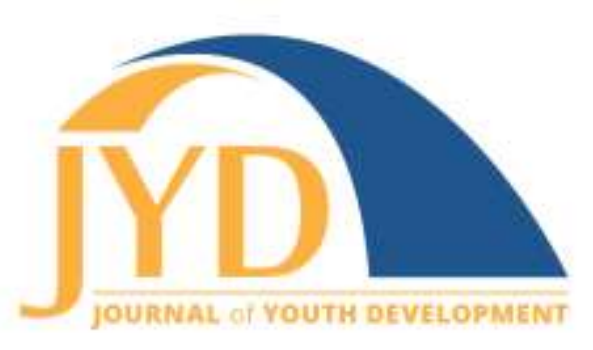

http://jyd.pitt.edu/ | Vol. 12 Issue 1 DOI 10.5195/jyd.2017.488 | ISSN 2325-4017 (online)

\title{
Social Justice Youth Work: Actualizing Youth Rights
}

\section{Monica McDaniel}

Augsburg College

monicakmcdaniel@gmail.com

\begin{abstract}
This article explores models of prevention/intervention and positive youth development within the context of social justice. Both of these models seek to support young people, but they have vastly different methods and goals. The author argues that these models fall short of effectively supporting youth because they neglect to interrogate how power, privilege and oppressive forces shape a young person's identity and how that young person engages with society. Therefore, a new approach to working with youth is needed: a social justice youth work model. The author proposes this model as a means for youth and adults to work together to achieve a high quality of life in an equitable world. The paper outlines three steps to enact this approach with young people: 1 . develop self-awareness within youth and adults; 2. build solidarity across differences; and 3. take action towards dismantling unjust systems. In order to do this work successfully, adults must first interrogate their own motivations for engaging in social justice work with youth.
\end{abstract}

\section{Introduction}

The field of youth work needs to shift its focus away from prevention/intervention and positive youth development models to one that examines the complex social, economic and political forces that affect the lives of young people and adults. Social and economic patterns of racism, sexism, classism and homophobia are some of the main issues confronting youth today. Models of prevention and intervention target specific groups of young people, claiming that certain youth are more likely than others to make destructive decisions. Positive youth development models shifted this paradigm to one focusing on the strengths of young people and positive supports in their lives. However, positive youth development emerged from the same belief of prevention/intervention that young people need to be changed and molded by adults into productive members of society. This mold is one of the dominant cultural framework: the straight, white, middle-class, able-bodied, cisgendered, American-born, Christian man. This is

(c) $\mathrm{EY}_{\mathrm{EY}}$ New articles in this journal are licensed under a Creative Commons Attribution 4.0 License. This journal is published by the University Library System, University of Pittsburgh and is cosponsored by the University of Pittsburgh Press. The Journal of Youth Development is the official peer-reviewed publication of the National Association of Extension 4-H Agents and the National AfterSchool Association. 
not the identity of the majority of society and expecting it to be denies a vast number of experiences where power, privilege and oppressive forces shape people's identities and the way they engage with society.

Social justice youth work is a third approach to engaging with young people that is distinctly different from prevention/intervention and positive youth development models. A social justice youth work model requires youth and adults to work together to achieve a high quality of life in an equitable world. This may seem utopian in nature, but the necessity for change is real and begins with an examination of self and an engagement in the injustices around us. In the collective work Octavia's Brood: Science Fiction Stories from Social Justice Movements (2015), writer, organizer, educator and spoken word poet Walidah Imarisha states,

Whenever we try to envision a world without war, without violence, without prisons, without capitalism, we are engaging in speculative fiction. All organizing is science fiction. Organizers and activists dedicate their lives to creating and envisioning another world, or many other worlds. (Imarisha \& brown, 2015, p. 3)

Even if a more equitable world is currently science fiction, it does not mean that youth and adults should continue to ignore injustice. Most of us are, in fact, largely responsible for perpetuating these injustices.

\section{Prevention/Intervention: Targeting the "Bad Kids" \& Overlooking the "Good Kids"}

In my neighborhood, there is a gas station with a prominent sign out front saying that only four youth under the age of eighteen are allowed inside at one time. When I asked the owner about the sign, he unleashed a litany of stories about chasing kids out of the store for knocking goods off of shelves while they yelled insults at him, about kids stealing bags of chips as they ran away laughing and how kids just seemed to always hang out there for way too long without buying a thing. He was frustrated and tired of the disrespect, so he put up the sign and reserves the right to kick anyone out who he feels will cross him. Unfortunately, this sentiment towards young people is not isolated to this one store owner and my neighborhood, but is a dominant perception of young people in communities across the country. One need only look at 'get tough on youth crime' public policy initiatives like those of the 1990s as the basis from which prevention and intervention approaches to youth development gained traction. 
In 1994 Minnesota passed the Juvenile Crime Act, a response to the perceived threat of an escalation in youth violence both locally and nationally. This act moved away from the original Progressive Era intent of the juvenile justice system of rehabilitation to one of punishment. According to the Juvenile Justice Coalition of Minnesota, this shift resulted in mandatory sentencing laws and more youth being tried as adults due to the simplification of transfer and waiver rules (Kreager, 2008). The response from youth advocates to these measures was one of prevention: the importance of social service institutions and community organizations to provide opportunities for youth to learn self-confidence and resiliency in order to "transition successfully into adulthood" (Kreager, 2008, p.5) without getting involved in the criminal justice system or saddled with burdens as a result of poor decisions. Youth who did get involved in the justice system were sometimes provided with court-ordered interventions depending on the level of offense and disposition made by the court. As much as these initiatives were wellintentioned approaches to advocate for and support young people, they, like the store owner's sign, sent a message to young people that they are feared and expected to make poor decisions. In no way did these initiatives address the underlying factors associated with why youth make these decisions. It was simply up to adults in positions of authority to guide youth down a more productive path.

With a heavy reliance on teen pregnancy, crime and drug statistics, certain neighborhoods, schools and age groups were selected for specific prevention programs. These early programs usually involved an adult with some authority coming into a school or community center to talk about the horrific atrocities that can happen as a result of poor decisions made by youth. The federally sponsored Drugs Abuse Resistance Education (D.A.R.E) program model of the 1980s and 1990s had this type of single-issue framework. A uniformed officer would get up to the podium in front of an entire class or school to talk about the amount of lives lost in the community due to drug overdoses. He'd show a few pictures with just enough graphic material to shock, but not scar the students, and then he'd share an emotional story of a young person, just like those in the room, whose life was forever changed because of a poor decision to use drugs. The program would then end with students taking a pledge to stay off drugs. Rosenbaum and Hanson (1998) found no difference with regard to recent and lifetime use of drugs between the students who had taken part in the D.A.R.E. program and those in the control group. D.A.R.E. has since gone through several iterations and its middling performance has sparked the development of a thorough certification process through Substance Abuse and Mental Health Services Administration (SAMHSA) to ensure more effective alcohol and/or drug education programs (Skager, 2007). 
Similar prevention and intervention programs, however, still exist today. They target young people who are perceived to be the greatest threat to communities or who are the most susceptible to get involved in the criminal justice or social services systems; these youth are deemed "at risk." At risk youth became a code phrase referring to young people of color and has expanded to a long list of youth in specific groups that includes youth in poverty; gay, lesbian, bisexual, transgender, queer, intersex and asexual (GLBTQIA) youth; and youth living in urban neighborhoods with high crime rates. Without examining oppressive factors in the lives of young people and the ways in which they might drive youth with these identities and experiences to make negative decisions, prevention programs suggest to young people that because of who they are and their environment, they are more likely to make poor decisions. This message is oppressive and can be detrimental both to youth involved in prevention programs and to youth who are not associated with one.

Youth who are not part of prevention and intervention programs are also ill-served by this targeted approach to youth development work. The message they receive can be quite damaging because it claims that youth with a majority of privileged identities are not in need of social services or intervention programming. Therefore, it can erase the very real issues buried within privileged, dominant cultural groups. Individuals with a majority of dominant cultural identities can be at risk as well. Oftentimes, they are the perpetuators of oppression in marginalized groups and/or they may experience oppression because they have both privileged and oppressed identities but attempt to pass within the dominant culture. Of the ten mass school shootings perpetrated by individuals under the age of 25 , all shooters were male and $70 \%$ were white (Mother Jones, 2017). Also, $62 \%$ of perpetrators of sexual assaults against women are white males; $49 \%$ are under the age of twenty-nine (United States Department of Justice, 2016). By focusing only on specific populations, especially those with marginalized identities, sources of problems within society can be missed or easily overlooked.

\section{Positive Youth Development Approach: Whitewashing Youth Experiences}

In the early 2000s, there was a shift in the youth development field away from prevention/intervention models towards positive youth development programming in out-ofschool-time settings. Longitudinal studies of prevention programs pointed to specific predictors of problem behaviors in youth and the programs' inabilities to demonstrate much positive influence over young people's choices and behaviors (Catalano, Berglund, Ryan, Lonczak, \& Hawkins, 2004). Therefore, a positive youth development approach was adopted, which 
embraced a strengths-based methodology in working with youth. Instead of focusing on the potential ways young people could get involved in the juvenile justice or social services systems, youth workers crafted a nurturing environment where they defined goals based on young people's capacities, strengths and developmental needs. Benard (1991) iterates that the three primary factors from the research on positive developmental outcomes was the presence of a nurturing climate that fosters caring relationships, high expectations and opportunities for contribution.

There is incredible power in an asset-based youth development model. As a white, middle class, female-identified young person in the 1990s and early 2000s, I was privileged to benefit from positive youth development programming without all of the prevention strings attached. In the nurturing environment of an all-girls summer camp, I built relationships with fellow campers and counselors that were foundational in shaping the person I am today. At the age of fifteen I was quite reserved and quiet, preferring the company of a book to the wholehearted engagement with others in program activities. Because of this, I had initially made the decision not to embark on the leadership opportunity awaiting my friends in the second two-week session of the summer: a nine-day Boundary Waters canoe trip. We were the oldest campers at camp and this trip, to us, was our rite of passage towards becoming camp leaders and potential counselors ourselves. I almost didn't go. It wasn't until my counselor, one of the leaders assigned to guide the canoe trip, approached me about why I had decided against this formative adventure with the rest of my friends. I still remember her sitting on the bench with me, nervously trying to draw me out. I honestly didn't have an answer for her, well not one that I had wanted to share. I was scared that I wouldn't be able to make it and that I had nothing to contribute. She seemed to think otherwise and said that I, out of anyone, would actually thrive. I took the weekend to think it over, bought a sleeping bag and signed up for the trip.

In the first few days, I learned quickly that we all had to depend on each other to stay dry, fed, and moving forward in good spirits. The high expectations set by our team pushed me to take the heavier canoe on a portage or the stern in big winds, to pride myself in overcoming the day's big challenge and supporting the group. My biggest boost in confidence came after a storm had pushed us off the lake fast and we had to crash a campsite for the night. While everyone was relaxing and drying off in the tent, I was exploring our new surroundings, now completely comfortable with the landscape and rhythm of our days. I was surprised when my leaders came to me saying that we were lost, asking if I knew how to read a compass. I 
thought it was some sort of test- that they wanted to see how I would do at trying on a new leadership role. It wasn't until they started disputing with each other about which way to go that I finally understood that we were lost, or at least a bit turned around. I was shocked that they were trusting me with this piece of news, believing that I would be helpful instead of panicking. So I didn't panic, took a look around and immediately knew exactly where we were, showing them how the map and compass lined up. The next morning, the group set off in the direction I had indicated and after passing a few unmistakable landmarks, it was clear we were on the right track.

Positive youth development can easily be summed up in a canoe trip. Trusting relationships are formed as your caring partner slaps mosquitos off your arms on a buggy portage. Expectations are high as you struggle to keep the canoe from tipping by pulling your paddle hard, stroke after stroke, through the water to keep the bow head-on into the waves of a windy lake. And everyone, not just the adults, leads the group with their own special gifts of laughter in a tough moment, thoughtful words around the campfire, hearty dinners deliciously seasoned from the spice kit, or the endurance to carry the heaviest load at the end of the day. There is no doubt that these guided life experiences build resiliency in young people.

However, Cammarota and Ginwright (2002) argue that positive youth development models shift too far in the other direction, away from any acknowledgement of the struggle in young people's lives that are associated with oppressive forces. These models can thus reinforce the exercise of certain privileges. Positive youth development models overcompensate by "promoting supports and opportunities as the only factors necessary for positive and healthy development of youth, and [do] not examine thoroughly the ways in which social and community forces limit and create opportunities for youth" (Cammarota \& Ginwright, 2002 p. 84). These models were also developed out of "universalistic, white, middle-class conceptions of youth" (Cammarota \& Ginwright, 2002, p. 85).

The experiences of a canoe trip and that of summer camp are steeped in a hidden history of oppression and exertion of privilege. Some of the same lakes and trails I traversed on my 'rite of passage' were those initially, solely walked by the Anishinabe people and later carved into trails by the indentured French-Canadian voyageurs of the exploitive and extremely profitable fur trade. By the time I arrived in those woods, their legacy existed only in names of the lakes we paddled (Lac la Croix) or in the food we ate (pemmican). Van Slyck (2010) explores the history of the American overnight summer camp experience that emerged out of the back-to- 
nature trend of the 19th century. With the rise of the middle class and a need for respite from the moral and physical degradations of urban life, Christian, European-American, middle-class professionals designed and built environments in which their children could spend their idle summers. Unfortunately, these nurturing environments did not include an analysis of how power, privilege and oppressive forces shaped these positive youth development experiences for young people.

The positive youth development experience at summer camp suited me well, for the most part. I was able to develop a certain level of self-awareness, an understanding of my strengths and areas in which to develop myself further. However, that self-exploration only scratched the surface of the effects of oppression and privilege on my development. Before the 1980s, my camp was for boys only. When girls were finally allowed, it chose to remain single-gender, hosting girls for half of the summer and boys for the other half. I believe this programming decision allowed female-identified campers to examine our diverse identities as girls and young women. At camp, we girls could defy oppressive stereotypes and be physically and emotionally strong, supportive to each other and confident in our internal and external beauty. However, we gave only a passing nod to and little discussion of identities that did not fall within the white, middle-class, heterosexual, cisgendered, able-bodied cultural framework. As a counselor who was questioning my own sexuality, I observed how gay and lesbian counselors revealed or concealed their sexual identities. Coming out was an individual's own decision at camp, but it was well understood that queer identities were not normalized within the camp culture. Due to the fact that only certain aspects of our identities were explored, our positive youth development camp experience did not go deep enough into the oppressive and privileged forces in our lives. Therefore, it limited opportunities and stifled healthy development, especially for those of us who fell outside of the dominant cultural framework. It also reinforced the exercise of privilege especially based around race, class and sexual orientation.

\section{Social Justice Youth Work: A Rights-Based Approach}

Positive youth development models that emerged in the early 2000s mirror those of the backto-nature American summer camp model: European-American professionals are still designing spaces for young people to spend their idle, out-of-school time, so they do not fall into the moral degradations wrought by our society. The diversity and number of summer program offerings have grown in urban, suburban and rural communities and they often call themselves 'camps.' However, the majority of these positive youth development models homogenize youth experiences into one of the hegemonic cultural frameworks of the European-American, straight, 
able-bodied, middle-class man. This needs to change. The oppressive environments wrought by this framework also need to change, not just for young people, but for adults as well. The majority of our society does not identify as a straight, white, middle-class, able-bodied, cisgendered, American-born, Christian man. Also there is a real possibility that no one can actually live up to society's narrow criteria for this ideal identity. Therefore, a more inclusive and truer framework is necessary. I suggest a third way: social justice youth work. Youth and adults should work together to achieve a high quality of life in an equitable world.

Social justice and youth work are both concepts that have many meanings and assumptions. However, when their origins and root definitions are examined, they both have the same foundation in the fundamental rights of individuals. Kay and Jost (2010) explain social justice as:

A state of affairs (either actual or ideal) in which (a) benefits and burdens in society are dispersed in accordance with some allocation principle (or set of principles); (b) procedures, norms, and rules that govern political and other forms of decision making preserve the basic rights, liberties, and entitlements of individuals and groups; and (c) human beings (and perhaps other species) are treated with dignity and respect not only by authorities but also by other relevant social actors, including fellow citizens. ( $p$. 1122)

Their definition is compiled from philosophical discourse where social justice is "a property of social systems" (p. 1122). This definition is quite broad, and is therefore open to many interpretations for what the actual benefits are in a society, what the basic rights of individuals should be, and what the measurable markers of respect to individuals are. This is where youth work can help to further explain social justice.

Young people exist within social systems that are unjust. In these social systems, they are learning, through observation of and interaction with peers and adults, how to engage with and navigate these unjust systems. The youth development models of prevention/intervention and positive youth development are part of the problem, "because they assume that youth themselves should be changed, rather than the oppressive environments in which they live" (Cammarota \& Ginwright, 2002, p. 85). The concept of youth work, unlike youth development, turns the focus away from molding young people into the ideal image of the dominant culture. By using the word 'work,' youth work implies action with young people towards something and 
the end result is not predetermined by adults or society's expectations. In a social justice youth work model, young people and adults work together in partnership to build their awareness of "how institutional, historical, and systemic forces limit and promote the life opportunities for particular groups" (Cammarota \& Ginwright, 2002, p. 87) and to take social action against oppressive forces. Prevention/intervention models have paved the way for social justice youth work to acknowledge and address social inequities. And positive youth development models have illustrated how a nurturing environment can be beneficial to a young person's selfdiscovery and self-efficacy. Through realizing the blind spots and strengths of both types of models, social justice youth work is able to move forward into common practice for individuals working with young people.

In Pedagogy of the Oppressed, Paulo Freire's (2000) approach to education is similar to that of social justice youth work. Freire believes that the initial step towards changing oppressive conditions is first coming to an understanding, or "conscientzaçao," (p. 67) that these conditions are not predetermined. Self-awareness in youth work begins with youth and adults exploring issues of identity through "an analysis of how power, privilege and oppression threaten their identities and capacity for self-determination" (Cammarota \& Ginwright, 2002, p. 89). This examination of self in this context easily leads young people and adults to think critically about the conditions in their immediate communities and how those connect to global systems of oppression within a historical context. Cammarota and Ginwright (2002) build on this concept by emphasizing that "people can only truly 'know' that they can exercise control over their existence by directly engaging the conditions that shape their lives" (p. 87). In this initial step of the social justice youth work model, youth workers can pull from best practice in positive youth development models: youth need opportunities for contribution. Youth workers should engage young people by encouraging them to name and explore their identities. Youth workers should then pull from the prevention/intervention models' acknowledgements that life experiences are not homogeneous. When youth workers and youth explore their identities and lean into how those identities have shaped their individual life experience and the experiences of others, they can begin to understand and unpack systems of oppression.

The second step in the social justice youth work model is to build solidarity across difference and come to voice to combat oppressive forces. Young people and adults have many intersecting identities, with some that are privileged within society and some that are marginalized. In Teaching to Transgress, bell hooks (1994) explains that "coming to voice is not just an act of telling one's experience. It is using that telling strategically-to come to voice so 
that you can also speak freely about other subjects" (p. 148). In this second step, youth workers can foster team building and dialogue with youth around their identities. Through these intentional activities, youth and adults are able to begin to understand the similarities and differences of individuals' experiences. True solidarity across difference occurs when self-aware individuals understand how the oppression of one identity intersects with and is connected to the oppression of other identities.

The third step within the social justice youth work model is for adults in partnership with young people to take action towards dismantling systems of oppression. This is the true purpose of youth work. The ideas of what action to take and how to enact change must come from the individuals in the group and grow out of the group's organic, consensus-driven process from steps one and two in the social justice youth work model. These three steps bring together the best practices of prevention/intervention and positive youth development models to dig deeper into the systems affecting youth and adults and promote the underlying necessity to address social and economic patterns of racism, sexism, classism and homophobia.

\section{How Do We Move Forward?}

Adults, we have some work to do. We cannot continue, like the gas station owner, to tell young people what to do and how to be, especially when we have hidden messages and assumptions about what mistakes youth are likely to make because of their gender, perceived race, socioeconomic status, sexual identity, etc. In the words of Teju Cole (2012), "If we are going to interfere in the lives of others, a little due diligence is a minimum requirement" (para. 1). Our due diligence is to change our want to have a "big emotional experience that validates privilege" (Cole, 2012, Tweet 5), to our actual need to self-examine how our own privileges and ways we may be oppressed affect the lives of young people and the lives of those around us. Only then can we authentically partner with young people to work towards changing the oppressive forces in all of our lives.

Prevention/intervention and positive youth development models are based on the same fundamental argument that young people need to change and they therefore discount the oppressive forces that youth are navigating. In his article, "When Language Loses its Bite," freelance writer Zahir Janmohamed (2015) examines the effectiveness of human rights work. He says,

But in discussing human rights, we seem to be stuck on two questions: is human rights work effective? and has it really 
achieved anything? If we measure the success of human rights advocacy by the decrease in human rights violations worldwide, then the answer is a resounding no. (para. 8)...However in thinking about human rights,...if you want to move an audience, use specific language-in short, name names. This, I believe, is the power of poetry and it is also the power of human rights work. It is the ability and the willingness to say things that we often bury. (para. 9)

Social justice youth work is human rights work. This collaborative effort allows youth and adults to name names, which starts with naming ourselves and the stories we bury. Unfortunately, our attempt to hold on to our privileges is at the expense of someone else's rights. Therefore it is important to ask ourselves, as youth workers, some important questions that a supervisor once had me explore: Why do I work with youth? Why am I working with this particular population of youth? Why do I work with them in this space/location? and Why do I work with youth in this way? There are no wrong answers to these questions, but they are a necessary beginning for any adult who wants to engage in social justice youth work and who has explored the ways in which their privileged and oppressed identities intersect and diverge from those of the young people with whom they work. Many of our struggles as adults are also the struggles of young people, so we need to do our due diligence to ensure that we are not perpetuating oppressive cycles.

In the words of social justice activist adrienne maree brown, "We hold so many worlds inside us. So many futures. It is our radical responsibility to share these worlds, to plant them in the soil of our society as seeds for the type of justice we want and need" (Imarisha \& brown, 2015, p. 279). We need to make sure that young people and adults have spaces in which to share their stories and engage the world in order to change it.

\section{References}

Benard, B. (1991). Fostering resiliency in kids: Protective factors in the family, school, and community. Portland, OR: Northwest Regional Educational Laboratory.

Cammarota, J., \& Ginwright, S. (2002). New terrain in youth development: The promise of a social justice approach. Social Justice, 29(4), 82-95. 
Catalano, R. F. , Berglund, M. L., Ryan, J. A. M., Lonczak, H. S., \& Hawkins, J. D. (2004). Positive youth development in the United States: Research findings on evaluations of youth development programs. The ANNALS of the American Academy of Political and Social Science, 591, 98-124.

Cole, T. (2012, March 21). The White-Savior industrial complex. The Atlantic. Retrieved from http://www.theatlantic.com/international/archive/2012/03/the-white-savior-industrialcomplex/254843/

Freire, P. (2000). Pedagogy of the oppressed. New York, NY: The Continuum International Publishing Group.

hooks, b. (1994). Teaching to transgress: Education as the practice of freedom. New York, NY: Routledge.

Imarisha, W., \& brown, a. m. (Eds.). (2015). Octavia's brood: Science fiction stories from social justice movements. Oakland, CA: AK Press and the Institute for Anarchist Studies.

Janmohamed, Z. (2015, May 31). When language loses its bite. Retrieved from CounterArchives website at http://counterarchives.org/2015/06/01/when-language-loses-itsbite-by-zahir-janmohamed/

Kay, A. C., \& Jost, J. J. (2010). Social justice: History, theory and research. Handbook of Social Psychology (pp. 1122-1165). New York, NY: New York University, Department of Psychology.

Kreager, C. (2008). Understanding the "systems" in juvenile justice: A map of Minnesota's juvenile justice system. Juvenile Justice Coalition of Minnesota. Retrieved May 20, 2015, from: http://www.jjcmn.com/public/2010/04/JJC-Juvenile-Justice-System-Handout.pdf

Mother Jones. (2017). US mass shootings, 1982-2017: Data from Mother Jones' investigation [data file]. Retrieved from http://www.motherjones.com/politics/2012/12/massshootings-mother-jones-full-data 
Rosenbaum, D., \& Hanson, G. (1998, November 1). Assessing the effects of school-based drug education: A six-year multilevel analysis of Project D.A.R.E. Journal of Crime and Deliquency, 35(4), 381-412.

Skager, R. (2007, November). Replacing ineffective early alcohol/drug education in the United States with age-appropriate adolescent programmes and assistance to problematic users. Drug and Alcohol Review, 26, 577-584.

United States Department of Justice. (2016). Female victims of sexual violence, 1994-2010 [data file]. Retrieved from https://www.bjs.gov/content/pub/pdf/fvsv9410.pdf

Van Slyck, A. A. (2010). A manufactured wilderness: Summer camps and the shaping of American youth 1890-1960. Minneapolis, MN: University of Minnesota Press. 